This item was submitted to Loughborough's Research Repository by the author.

Items in Figshare are protected by copyright, with all rights reserved, unless otherwise indicated.

\title{
Interpersonal relationships in transnational, virtual teams
}

PLEASE CITE THE PUBLISHED VERSION

http://www.palgrave.com/

\section{PUBLISHER}

Palgrave Macmillan

VERSION

AM (Accepted Manuscript)

LICENCE

CC BY-NC-ND 4.0

REPOSITORY RECORD

Zimmermann, Angelika. 2019. "Interpersonal Relationships in Transnational, Virtual Teams". figshare. https://hdl.handle.net/2134/9880. 
This item was submitted to Loughborough's Institutional Repository (https://dspace.lboro.ac.uk/) by the author and is made available under the following Creative Commons Licence conditions.

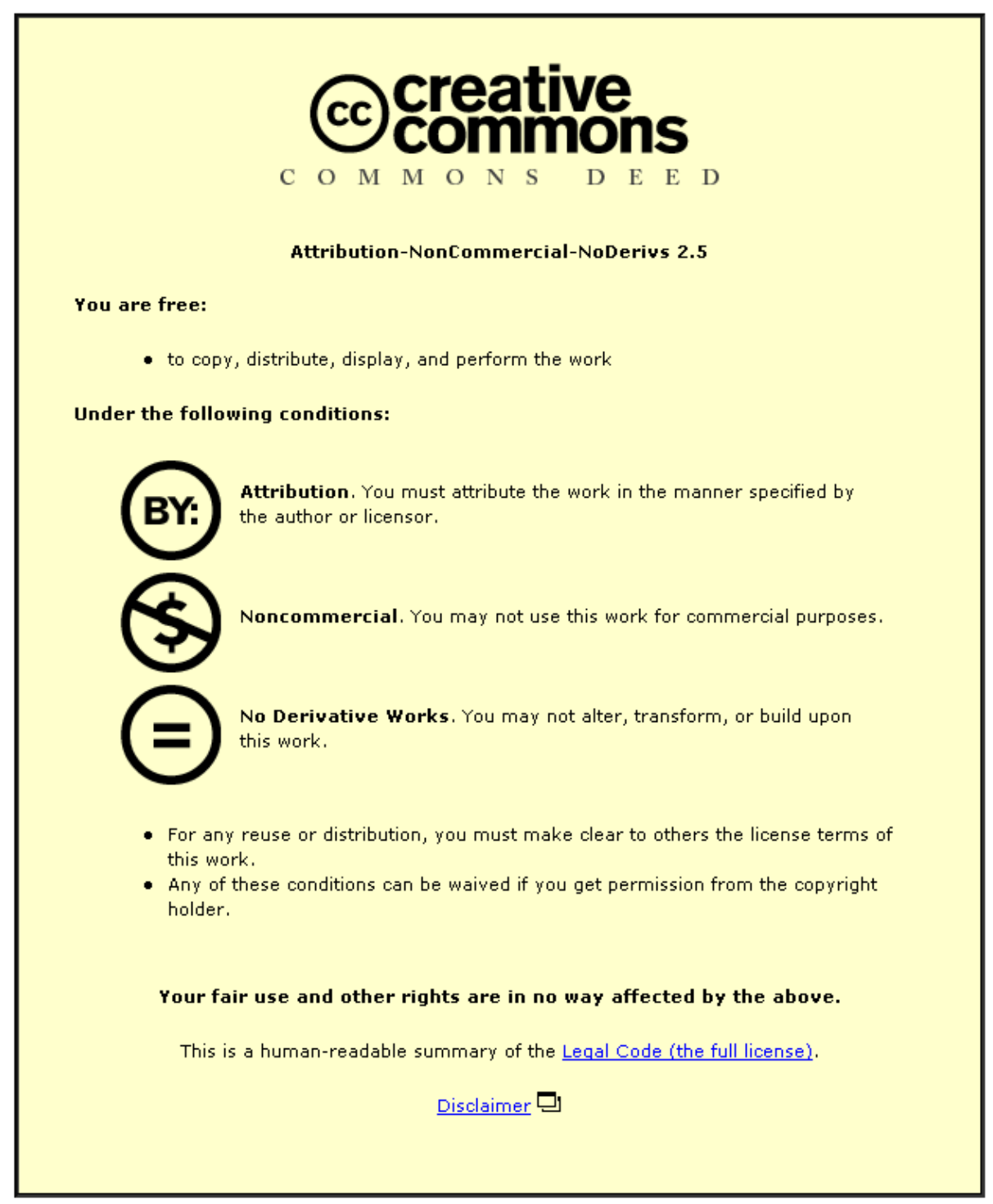

For the full text of this licence, please go to: http://creativecommons.org/licenses/by-nc-nd/2.5/ 


\title{
Interpersonal relationships in transnational, virtual teams - towards a configurational perspective (CP)
}

\begin{abstract}
This article uses a literature review to develop a configurational analysis of interpersonal relationships in transnational teams (TNTs). The configurational appraoch posits that organisational reality cannot be explained by uni-directional, causal relationships between isolated variables, but only in terms of variable configurations, i.e. 'multidimensional constellations of conceptually distinct characteristics that commonly occur together' (Meyer et al. 1993, p. 1175). The effect of single variables is seen to depend on their interaction with the multitude of other variables in a configuration.

TNTs are defined as groups composed of members of different nationalities, who work on a common task. Previous research on TNTs has observed that strong interpersonal relationships are especially important for the functioning of these teams, but are at the same time particularly hard to achieve. Moreover, many studies have singled out particular processes that will here be termed 'aspects' of relationships. This article firstly integrates the transnational and virtual team literature to provide an overview of examined relationship aspects. The article identifies cognitive relationship aspects, which encompass team identity, subgroup formation, shared understanding, and trust. Communication, knowledge creation, and conflicts are described as behavioural aspects, and interpersonal affect is identified as an affective relationship aspect.

These relationship aspects are regarded as elements of complex relationship configurations. The paper therefore describes the influence of each of these aspects on other relationship aspects, thereby demonstrating complex interconnections between relationship aspects. This provides a first step towards a configurational analysis. The paper further reviews how several characteristics of the team structure, organisational context, and socio-political environment may facilitate or inhibit several relationship aspects. Special emphasis is placed on the influence of cultural diversity and virtuality as the two factors that are characteristic of TNTs, and which have also been discussed most frequently in the literature.

Through a synthesis of previous research, the article then provides an overview of suggested mutual influences between relationship aspects. This leads to a suggestion of two examples of relationship configurations and their driving factors. These configurations are characterised by the orchestrating themes of 'commitment and tight coupling' and 'commitment and loose coupling', respectively. The paper concludes by recommending methods for future empirical research on relationship configurations in TNTs. It argues that a broad range of relationship aspects needs to be included in such research, to examine relationships across a number of different team structures and organisational contexts, and in different socio-political environments. In-depth, qualitative case research is the most suitable for exploring this complex social phenomenon.
\end{abstract}




\section{INTRODUCTION}

Over the last decade, research on transnational teams (TNTs) has grown from a small, specialist area into a major stream of interest covering several disciplines. TNTs have been investigated by social psychologists as well as experts on international business and information systems. This has led to the first literature reviews (Berg 2006; Connaughton and Shuffler 2007; Podsiadlowski 2002; Stahl et al. 2007) and an edited book on the subject (Shapiro et al. 2005). Given that TNTs are often geographically dispersed, many TNT studies include issues of virtual collaboration.

Due to the importance of transnational, virtual teams for international organisations, many researchers have focussed on what makes these teams effective. One central, repeated observation is that positive, effective relationships amongst TNT members are especially important for TNT success, but are at the same time particularly hard to achieve (e.g., Gibbs 2006; Gibson and Manuel 2003; Gluesing and Gibson 2004; Maznevski et al. 2006). On a broad level, interpersonal relationships in TNTs can be defined as the ways in which team members relate to each other, which includes cognitive, behavioural, and affective aspects. Some researchers have emphasised the importance of interpersonal relationships in TNTs by referring to the encompassing framework of social capital, which highlights the significance of relationships as a resource of social action (Nahapiet and Ghoshal 1998, p. 242). Others have used the related theory of social networks to characterise the complex, internal and external links of TNT members and the shifting boundaries of TNTs (Joshi et al. 2002; Maznevski and Anthanassiou 2006). Moreover, many studies have singled out particular processes that will here be termed 'aspects' of relationships, such as trust or communication. Some of these studies describe interconnections between certain relationship aspects, providing reasons to assume that there may be many more, unrevealed interrelations. 
What is to date missing is a comprehensive overview of the most significant relationship aspects in TNTs and their interconnections. This selective literature review aims to sketch such a broad picture from what has been examined so far. It focuses on the transnational and virtual team literature as opposed to including any relevant theory and research, to highlight the distinctive characteristics of relationships in transnational, virtual teams. Previous research will be integrated to identify suggested interrelations between different relationship aspects. Thereby, this review will deviate from the prevalent linear Input-Process-Output models of team functioning that follow classic system models (e.g., Hackman and Oldham 1980; McGrath 1984). Instead, it will make a first step towards a non-linear systems analysis and, through this, a configurational perspective on relationships in TNTs.

\section{$\underline{\text { Non-linear systems, configurations }}$}

The non-linear systems approach claims that social systems tend to consist of a multitude of elements that influence each other reciprocally, making it impossible to clearly distinguish cause and effect (see Mendenhall 1999, for a review). The configurational perspective, in turn, has been developed in organisational theory (e.g., Miller 1990, 1996). It posits that organisational reality cannot be explained by uni-directional, causal relationships between isolated variables, but only in terms of variable configurations, i.e. 'multidimensional constellations of conceptually distinct characteristics that commonly occur together' (Meyer et al. 1993, p. 1175). The effect of single variables depends on their interaction with the multitude of other variables in a configuration. In this review, two examples of theoretically likely configurations of TNT relationships and their determining factors will be proposed (Table 1).

\section{Definitions and overview}

The term 'team' is here used broadly to designate a group of people working on a common task. The term 'transnational, virtual teams' was chosen to designate research that focuses on 
transnational, i.e., international, multinational, multicultural, cross-cultural or global teams which are at the same time virtual, i.e. geographically dispersed and collaborating with the help of electronic communication media. The label 'transnational' is here regarded as more generic than 'multinational' or 'multicultural', because it comprises teams composed of either many or only two nationalities, and it includes diversity of nationality, rather than only cultural diversity. All of these terms were used for a web based literature search. Both empirical and conceptual papers and book chapters were included when they made a significant contribution to the leading questions. Figure 1 provides an overview matrix of the relationship aspects and their influences on each other as indicated by the reviewed literature.

\section{INSERT FIGURE 1 ABOUT HERE}

Relationship aspects prominent in the literature will be presented in the sequence shown in Figure 1. I first discuss aspects classified as 'cognitive', including team identity, subgroup formation, shared understanding, and trust. I then turn to behavioural aspects in terms of communication, knowledge creation, and conflicts, before describing the affective aspect 'interpersonal affect'. Throughout, I summarise what has been said about the function of these aspects, both with regard to team performance and their influence on other relationship aspects, particularly those discussed in this review. The next focus will be on cultural diversity and virtuality as the two characteristics of the team structure that have been discussed most frequently and with regard to all relationship aspects. It is demonstrated how they make effective relationships more important but at the same time often harder to achieve in TNTs. However, diversity and virtuality can also have certain positive effects on relationship aspects. As the discussion progresses, I will outline how each newly introduced relationship aspects relies on those mentioned before. This will demonstrate that diversity and virtuality have a further, indirect influence on relationship aspects through these interconnections. When discussed in the literature, 
it is further explained how each relationship aspect relates to a number of other factors. Within the team structure, many suggestions have been made regarding team leadership, shared goals, and task interdependence. Only a few insights have been developed regarding the influence of the organisational context, in particular subunit interdependence and localisation-integration strategies, as well as socio-political context factors. To draw conclusions, I highlight the main insights regarding non-linear systems and configurations, develop configuration examples, and make a number of suggestions for future research.

\section{COGNITIVE ASPECTS OF RELATIONSHIPS IN TNTs}

\section{Team identity}

Team identity has been claimed to be a key facet of social capital (Nahapiet and Ghoshal 1998, p. 244) and is therefore a crucial aspect of relationships in TNTs. Team identity and identification are commonly explained on the basis of social categorisation and social identity theory. Social categorisation theory posits that people form their initial impressions of each other according to social categories (Turner 1987). Social identity theory, in turn, suggests that individuals identify with a group (their 'ingroup') on the basis of their perceived degree of similarity with others, which in turn depends on their social categorisation of self and others (Tajfel 1982).

A TNT can have a stronger or weaker team identity, i.e. stronger or weaker social identification of team members with the team as their ingroup. A strong TNT identity has been described as a ‘coupling mechanism’ (Gibbs 2006, p. 347), and, accordingly, strengthens various relationship aspects. Team identity has been linked to many other relationship aspects. It has been suggested to increase TNT members’ mutual trust (Henttonen and Blomqvist 2005; Maznevski et al. 2006; Zakaria et al. 2004), to motivate members to contribute their knowledge to the TNT (Fulk et al. 2005) and thus to create intellectual capital (Nahapiet and Ghoshal 1998). Hinds and 
Mortensen (2005) found that team identity moderates the effect of geographic distribution on interpersonal conflicts in TNTs.

A strong team identity appears to be more difficult to achieve in TNTs compared to mono-national teams. The main factors within the team structure are cultural differences and virtuality. For example, Shapiro et al. (2002) suggest that limited socio-emotional understanding due to cultural differences makes it more difficult to achieve team identity, whilst also making it more relevant. They further reason that team identity formation is restrained by virtuality and reliance on electronic communication media, leading to a lack of visibility of team members' faces and of personal, informal bonding.

\section{$\underline{\text { Subgroup formation }}$}

Subgroups in teams are typically understood to form along 'faultlines', i.e. hypothetical dividing lines which split a group into subgroups according to members' shared core attributes (Lau and Murnighan 1998, p. 328). In TNTs, nationality characteristics, such as appearance, language, values, legal and economic systems, are likely to be the salient attributes that form the basis of subgroup identities (Gibson and Grubb 2006). Multinational group members are therefore likely to categorise members of other nationalities as part of 'outgroups' and evaluate them less positively than ingroup members (Gibson and Grubb 2006, p. 72). Accordingly, Joshi et al. (2002), applying a social network analysis, demonstrate that TNT members in their case study formed subgroups according to national subsidiaries.

When examining the relation of subgroup formation with other relationship aspect, it becomes apparent that subgroup formation may have either negative or positive effects on team functioning. Early and Mosakowski (2000) found that strong faultlines in TNTs were related to low levels of team identity, communication problems, and relational conflict. In the same vein, Cramton (2001) reports that polarised groups withheld information from each other, which 
implies limited knowledge creation. Accordingly, Cramton and Hinds (2005) suggest that subgroup formation in international teams can lead to ethnocentrism, which entails negative evaluation of the other subgroup, and relationships marked by competition and conflict.

However, subgroups are not always detrimental for team functioning and may even have positive effects on other relationship aspects (see Panteli and Davison 2005; Stahl et al., 2007). Gibson and Vermeulen (2003) demonstrated that when subgroups were moderately strong, i.e., a moderate amount of characteristics were shared within the subgroup (e.g., nationality), but a number of other characteristics were shared with members of other subgroups (e.g., profession), the team maintained an 'inclusive atmosphere' and subgroups stimulated team learning, a form of knowledge creation.

The effect of subgroups on team functioning seems to depend on various factors within the team structure, such as the prevalence of super-ordinate, shared team goals, acting as a bridging mechanism in TNTs that strengthens team identity (e.g., Earley and Gardner 2005; Earley and Gibson 2002; Mcdonough and Cedrone 2000). Moreover, the team leader can take an important role in stressing similarities of group members across national subgroups, and in emphasising shared group goals (e.g., Davison and Ward 1999).

Shared understanding

It is essential for TNTs to achieve a shared understanding of various team and situation features, given its effect on other relationship aspects. For example, Shapiro et al. (2002) claim that limited socio-emotional understanding will weaken team identity. Shared communication codes, language, narratives (Baba et al. 2004) are seen to be necessary for exchanging information and thereby creating knowledge. Hinds and Mortensen (2005) found that shared context moderates the effect on team member distribution of task-related conflict. Team members' perception of a shared understanding can further create positive affect and trust (Klimoski and Mohammed 
1994). According to Sutanto et al. (2005), a shared, organised knowledge structure enhances not only social interactions, but also task performance of a TNT.

As with team identity, TNTs are likely to face greater difficulties in achieving a shared understanding than mono-national teams, due to structural characteristics. Both cultural differences and physical distance tend to create a divergence of team members' perceptions of team and situation aspects (e.g., Gibson, 2009; Govindarajan and Gupta 2001). Shared understanding in TNTs is dependent on further structural characteristics, including team leaders who can, for example, design common goals (Earley and Mosakowski 2000).

\section{$\underline{\text { Trust }}$}

Trust has received wide attention in the TNT literature. Trust is usually defined on a cognitive level, for example as a 'willingness to be vulnerable to another party irrespective of the trustor's ability to monitor or control that party’ (Rousseau et al. 1998; cited in Earley and Gardner 2005, p. 11). Trust amongst TNT members is important for many other relationship aspects. Gibson and Gibbs (2006) demonstrate that trust supports innovation, hence knowledge creation, in TNTs, by helping to create a safe communication climate where team members are willing to express their ideas openly, communicate informally, and take risks. In the same vein, trust is argued to contribute to the creation of intellectual capital (Nahapiet and Ghoshal 1998).

However, building trust is more difficult in TNTs compared to collocated, mono-national teams and may therefore take longer to develop (Gluesing and Gibson 2004; Hambrick et al. 1998). Cultural and geographical distance can lead to negative subgroup processes, including mistrust towards outgroup members (Gibson and Manuel 2003), which can be based on negative stereotypes (Adler 1997). A number of additional factors of the team structure influence trust in TNT. Team leaders can facilitate the development of trust (Davison and Ward 1999; Govindarajan and Gupta 2001). Gibson and Manuel (2003) suggest that trust increases with 
higher interdependence of team members' tasks, outcomes, and resources, amongst others. Interdependence is seen to entail more frequent interactions, resulting in greater familiarity, thereby making it easier to judge each others’ trustworthiness. Earley and Gardner (2005) further claim that interdependence can be increased by shared goals. Organisational factors of trust in TNTs have not received explicit attention.

\section{BEHAVIOURAL ASPECTS OF RELATIONSHIPS IN TNTs}

\section{$\underline{\text { Communication }}$}

Communication is commonly defined in terms of information being transmitted from a sender, who encodes a message, to a receiver, who decodes the message in order to understand its meaning. Communication has a crucial impact on various relationship aspects in TNTs. TNT members need to communicate in order to develop a shared understanding about their expectations, rules, etc. (Earley and Mosakowski 2000, p. 36). As mentioned, communication is also important for building trust. It serves to obtain information about each other, thereby decreasing uncertainties and providing evidence for each others' trustworthiness. Moreover, unsolicited communication can demonstrate benevolence (Jarvenpaa et al. 1998). Not surprisingly, successful information sharing is necessary for creating knowledge. Moreover, spontaneous, informal communication was found to reduce interpersonal and task conflicts in global virtual teams (Hinds and Mortensen 2005).

Communication, like other relationship aspects, has been suggested to be more difficult and at the same time more crucial in TNTs compared to mono-national, collocated teams. TNT members' different cultural contexts can lead to disparities in communication codes, leading to misunderstanding (Adler 1997; Erez and Earley 1993; Hambrick et al. 1998). At the same time, communication is particularly important in TNTs, for getting to know one another's communication norms, values, etc. (DiStefano and Maznevski 2000; Maznevski 1994). The 
virtual team structure places further obvious constraints on communication. Virtual communication relies on non-synchronous and less rich media which provide less contextual cues and less immediate feedback than face to face communication. However, Connaughton (2007) points out that not just the amount of communication may be relevant for TNT functioning, but also its process in relation to its content. Maznevski and Chudoba (2000) demonstrate that successful TNTs used strong, regular patterns of communication, matching communication function with form, and adhering to face to face meetings at regular intervals.

Team leaders can take an important role in facilitating the appropriate form and frequency of communication through team building and creating shared goals (Davison and Ward 1999; Govindarajan and Gupta 2001), as well as designing task interdependence. Kumar et al. (2004) highlight that companies can circumvent barriers to communication in globally distributed teams by applying organisational strategies that serve to control interdependence between different subsidiaries.

\section{Knowledge creation}

Knowledge creation has received considerable attention as a desirable process and outcome of TNT work. It is often equated with team learning. For instance, Zellmer-Bruhn and Gibson (2006, p. 501) define team learning as the collective acquisition, combination, creation, and sharing of knowledge by teams. The importance of knowledge creation or team learning becomes apparent when considering its effect on other relationship aspects. Team learning regarding existing and new norms is required for creating a shared understanding. Successful knowledge creation is also likely to strengthen team members' trust in the team's competence.

Like the other relationship aspects in TNTs, knowledge creation and innovation are influenced by the cultural diversity and virtuality of TNT members. This influence can be positive, and some authors therefore stress that differences of culture and context should not be 
equalled out (Earley and Gibson 2002; Janssens and Brett 2006) but embraced (Gibson and Grubb 2005). In their meta-analysis of previous findings, Stahl et al. (2007) demonstrate that cultural diversity supported creativity, which is related to knowledge creation in multicultural teams. However, diversity and dispersion can also pose challenges to knowledge creation in TNTs. An important analysis by Fulk et al. (2005) emphasises that individuals have a tendency to respond to immediate local needs for knowledge sharing before the needs of the dispersed TNT. Moreover, knowledge tends to flow along pre-existing social ties (Fulk et al. 2005). Team members therefore have to be motivated to share their knowledge across national borders. Fulk et al. suggest that identification with the team is an important motivator, because it leads team members to value the collective benefit provided by the distributed knowledge commons. By contrast, as mentioned before, Gibson and Vermeulen (2003) demonstrated empirically that moderately strong subgroups can stimulate rather than impede learning in heterogeneous teams.

Successful knowledge creation depends also on several of the other relationship aspects, and is thereby further indirectly influenced by diversity and dispersion. This will be demonstrated in the following paragraphs. A rich picture of interrelations between relationship aspects should thereby emerge.

Fulk et al. (2005) posit that for effective knowledge sharing, TNT members have to develop a 'shared roadmap’ on where knowledge resources are located and how they should be accessed, which corresponds to a shared understanding in terms of a team mental model. Moreover, Zakaria et al. (2004) state that TNT have to create a knowledge sharing culture, which rests, amongst others, on the existence of mutual trust. Similarly, Fulk et al. highlight that trust is particularly important for team members to share their knowledge across the distance, where contributions are less visible and cannot be monitored. Conversely, distance is seen to be an 
obstacle for trust. Mcdonough and Cedrone (2000) demonstrated a lack of information sharing in common electronic workspace due to a reduced sense of security in TNTs.

Obviously, knowledge creation relies critically on information exchange via communication. Oshri et al. (2008) demonstrate that frequent teleconferences and occasional short visits were necessary for developing a team mental model of 'who knows what' in globally distributed teams, which is required for creating knowledge.

Knowledge creation can be influenced by the same factors that affect the other relationship aspects, both indirectly, through the ties with these aspects, and directly. Fulk et al. point out that the development of a transactive memory system relies on interdependence amongst team members (which would include interdependence of tasks and subunits). ZellmerBruhn and Gibson (2006) demonstrate that the organisational strategies of local responsiveness versus global integration affect learning in TNTs. They explain that local responsiveness provides local offices with more independence, which is necessary for initiating new processes and products. Moreover, local responsiveness requires several functions (R\&D, etc) to be located at the subsidiary. This leads to interdependence with other subsidiaries and the need to share perspectives.

\section{$\underline{\text { Conflicts }}$}

TNT research has examined task and relationship conflict, and, to a lesser extent, process conflict (Mortensen and Hinds 2001; Stahl et al. 2007). Task conflict relates to perceived differences in views referring to tasks. Relationship conflict is concerned with interpersonal incompatibilities and is typically associated with interpersonal affect, such as tension. Process conflict refers to disagreements about the ways to complete a task. Relationship conflict has consistently been associated with process losses and decreased performance. This can be explained by the effect of conflicts on other relationship aspects. For example, Earley and Mosakowski (2000) 
demonstrated that affective conflicts were associated with less effective team identity and communication in TNTs. Task conflict can, in contrast, have either positive or negative effects, depending on the nature of the task. Constructive conflicts between contrasting views may be necessary to create a shared understanding (Tuckman 1987). Constructive arguments concerning task-related disagreements are seen to lead to more information sharing (part of communication) and careful analysis, but may inhibit performance on highly complex tasks (De Dreu and Weingart 2003). TNT are often set up to capitalise on diverse knowledge and ideas. Constructive conflicts should therefore be particularly useful for knowledge creation (e.g., Earley and Gibson, 2002). A number of researchers have addressed the question whether TNTs face more conflicts than collocated, mono-national teams. Cultural differences and virtuality are again the main distinguishing factors. There are many reasons why cultural differences could increase conflicts in TNTs, but results are inconclusive. Members of different cultures hold different views on what justifies conflict, what can be classified as a conflict, and on appropriate ways of dealing with conflicts (Davison and Ekelund 2004). Von Glinow et al. (2004) therefore suggest that emotional conflict is more likely and harder to solve in multicultural teams. Accordingly, the meta-analysis of studies on multicultural teams by Stahl et al. (2007) demonstrated that cultural diversity was significantly related to task conflict, but not to relationship and process conflict. With regard to virtual TNTs, Elron (1997) found a positive effect of national diversity on issue-based conflict, whilst Kankanhalli et al. (2007) demonstrated that cultural diversity contributed to both task and relationship conflict.

Geographic distribution can increase conflicts by reinforcing subgroups along national faultlines. Through a social network analysis, Joshi et al. (2002) demonstrate that each conflict in the TNT of their study occurred mainly between subsidiaries. Moreover, Cramton (2001) demonstrate that TNT members' lack of understanding of each others' context lead to harsh, 
categorical attributions and therefore increased conflict when distant member did not provide sufficient information. On the other hand, Montoya-Weiss et al. (2001) suggest that asynchronous, virtual communication can make aggressive emotions less noticeable. Stahl et al.'s (2007) meta-analysis demonstrates that in geographically dispersed teams, cultural diversity was associated with lower levels of conflicts than in collocated teams. This discussion demonstrates that conflict in TNTs is dependent on the degree and type of communication amongst team members.

Conflicts are also closely tied to several other of the fore-mentioned relationship aspects. Hinds and Mortensen (2005) found that spontaneous communication had not just a direct effect on conflicts in TNTs, but also an indirect effect, by strengthening shared context and shared identity. Shared identity is explained to eliminate ingroup-outgroup behaviours, lead to less negative evaluations of each others' behaviour, and to more cooperative behaviour when conflicts occur. As mentioned, trust is another prerequisite for solving conflicts.

Conflicts in TNTs are influenced by many of the previously examined factors. Relationship conflicts may be less detrimental when task interdependence is low (Kankahalli et al. 2006). Team leaders can take a role in monitoring conflict (Davison and Ekelund 2004). They can control information exchange by using temporal coordination mechanisms to ensure conflicts are recognised and dealt with at an early stage (Montoya-Weiss et al. 2001). Shared goals, in turn, can help foster team identity and may thereby reduce conflicts (Earley and Mosakowski 2000). The effect of the organisational context has not been investigated explicitly.

\section{AFFECTIVE ASPECT OF RELATIONSHIPS IN TNTs}

Affective relationship aspects have not been a major focus of TNT research. However, to many of the discussed cognititive and behavioural aspects have been related to interpersonal affect. $\underline{\text { Interpersonal affect }}$ 
Interpersonal affect in TNT can be defined as the positive or negative feelings that team members hold towards each other, which includes liking and dislike (Joshi et al. 2002) as well as attraction, attachment, and affection (Jarvenpaa and Leidner 1999). Interpersonal affect is influential for many other relationship aspects. Interpersonal attraction due to trait similarity is a reason for identifying with a subgroup (e.g., Adler 1997). Positive affect (i.e., positive feelings that team members hold towards each other), as well as conveying attraction and affection by taking the initiative to respond to each other, may fuel a propensity to trust in TNTs (Earley and Mosakowski 2000, p. 27; Jarvenpaa and Leidner 1999, p. 811). Negative affect, including tension, dislike, and annoyance, are defining symptoms of affective conflict (e.g., Mortensen and Hinds 2001), making it hard to distinguish whether negative affect causes or results from affective conflict.

Positive affective ties may be more difficult to achieve in conditions of cultural diversity and virtuality. Adler (1997) suggests that multinational team members are likely to be less attracted to members of the national outgroup and will therefore develop more dislike. Both cultural differences and virtual collaboration may also inhibit positive affect indirectly, through their influence on other relationship aspects.

Whilst factors within the TNT structure and the organisational context have not been examined with regard to interpersonal affect, Jelinek and Wilson (2005) as well as Hambrick et al. (1998) point out that features of the socio-political context, namely the historical and current relationships (e.g., animosities) between countries may cause a certain affect (e.g., tension) between individuals, regardless of their cultural distance.

\section{CONCLUSIONS}

$\underline{\text { Nonlinear systems and configurations in TNTs }}$ 
This review has provided an overview of the examined complex interrelations between relationship aspects in TNTs. The matrix in Figure 1 aims to clarify this picture. Importantly, the matrix of Figure 1 is confined to the suggestions made in the reviewed literature and can therefore only provide an indication of existing interrelations. In the reviewed literature, influences in one direction or the other were suggested for the majority of combinations of aspects. Moreover, mutual influences with other aspects were shown for team identity (mutual influence with 3 other aspects), subgroup formation (with 2 other aspects), shared understanding (with 3 other aspects), trust (with 3 other aspects), communication (with 4 other aspects), knowledge creation (with 2 other aspects), conflicts (with 4 other aspects), interpersonal affect (with 2 other aspects). Many more interrelations are likely to exist.

By demonstrating complex interrelations and several mutual influences between an integrated set of relationship aspects, this review has followed the approaches of non-linear systems and configurations. As mentioned in the introduction, the non-linear systems view claims that social systems tend to consist of a multitude of elements that influence each other reciprocally, making it impossible to clearly distinguish cause and effect (Mendenhall, 1999). In the review, certain influences between different relationship aspects had to be isolated in order to allow for a clearer analysis, rather than analysing more complex interaction effects. It was thereby possible to suggest certain cause and effect relations theoretically. However, the array of mutual influences suggests that in practice it may not be possible to distinguish cause and effect. From this review, it is possible to suggest typical factor-relationship configurations under consideration of the more frequently examined factors, i.e. factors within the team structure. These are cultural diversity, virtuality, task interdependence, team leadership, and shared goals. Based on a synthesis of the reviewed research, two possible configurations are suggested (Table 1). These two configurations were chosen to demonstrate that positive relationships can be 
achieved by different constellations of relationship aspects, depending on the overall configuration of factors and relationship aspects. The focus is thus on the ambiguous effects outlined in the literature. Two orchestrating themes were identified: 'commitment and tight coupling' and 'commitment and loose coupling'.

Configuration 1 is characterised by the orchestrating theme of 'commitment and tight coupling'. Relationships in this configuration are positive, because the potential negative effects of strong cultural differences and virtuality are reduced despite high task interdependence, through integrative team leadership and using shared goals. Configuration 2 follows the orchestrating theme of 'commitment and loose coupling'. Cultural differences and virtuality are strong, and integrative leadership is weak. Nevertheless, the TNT's relationships function well, because the team has strong shared goals, and relationships are less relevant due to low task interdependence.

\section{INSERT TABLE 1 ABOUT HERE}

Subgroup formation is moderate in configuration 1 and supports team learning, as the integrative leader fosters an inclusive atmosphere (Gibson and Vermeulen 2003) and a strong team identity. In configuration 2, subgroups are strong, but the shared goals support a strong team identity and thereby help circumvent the potential negative effects of subgroups, even though integrative leadership is weak. The subgroups can thus arrive at sufficiently effective communication with each other and avoid relational conflicts (Earley and Mosakowski 2000). Team learning will occur rather within the local subgroups than the whole team (Zellmer-Bruhn and Gibson 2006).

In configuration 1, the close cooperation and frequent communication required by task interdependence, as well as the integrative leader, will help achieve a shared understanding of roles and norms, leading to effective communication and high levels of trust. In configuration 2, 
shared understanding may be weaker, leading to less effective communication and possibly lower trust (see Kumar et al. 2004), which can impede knowledge creation. However, the shared goals and strong team identity will motivate team members to exchange sufficient knowledge between subgroups where necessary.

Conflicts are likely to be constructive in both configurations, given the strong team identity and shared goals. In configuration 1, the high levels trust and shared understanding will additionally serve to solve conflicts, whilst relationship conflicts will be less detrimental in configuration 2, given the low task interdependence (Kankahalli et al. 2006).

Interpersonal affect, positive and negative, is likely to be more developed in configuration 1, due to weaker subgroups, stronger communication and understanding, and better personal acquaintance through close cooperation with interdependent tasks. This will further affect trust, knowledge creation, and conflicts.

From these two examples, several other configurations can be inferred, such as a configuration of strong cultural diversity and virtuality in combination with weak leadership and goals as well as high interdependence, likely to trigger several negative relationship dynamics.

Interestingly, the second configuration example accords with Gibbs’ (2009) finding that 'dialectical tensions' in a global software team were not detrimental to team interactions, as long as the tensions were managed and negotiated well. Configuration 2 suggests that, instead of aiming at the highest possible degree of integration, it is possible to achieve effective interpersonal relationships despite strong subgroups, less clear role expectations, and incomplete shared understanding. This also accords with findings by Zimmermann and Sparrow (2007), who demonstrate that TNTs worked effectively by balancing integration and differentiation of interaction styles and work practices.

$\underline{\text { Research agenda }}$ 
This review suggests that future research should include a broad array of relationship aspects and factors to systematically identify more comprehensive configurations of both relationship aspects and factors, and their association with each other. This would not render former IPO models invalid, but would demonstrate the degree to which they simplify the complex, larger picture. IPO models risk missing crucial interaction effects, but they allow for a simplification that helps examine the mechanisms of influences between certain relationship aspects in more depth. Results from such analyses can be used to inform more holistic, but typically less detailed, configuration research. For practitioners, such an overview of relationship and factor configurations could provide valuable recommendations on sets of strategic and management practices that can support positive relationship configurations under particular structural and organisational conditions. Focusing only on a few variables in isolation may not help achieve effective TNT relationships, given their interactions with other elements of the configuration.

To conduct such research on typical configurations, it would be necessary to include a broad range of relationship aspects across a number of different team structures and organisational contexts, and in different socio-political environments. In-depth, qualitative case research would be the most suitable to explore this complex social phenomenon, allowing for rich descriptions and explanations of various relationship configurations and their dependence on configurations of factors in specific team structures, organisational contexts, and socio-political contexts. Comparative, multiple case studies of different teams and companies would be particularly useful for highlighting the structural and context influences. Real life organisations are the suitable context for revealing existing configurations. Field experiments, in turn, which do not eliminate the rich real-life context, could be set up to systematically investigate configurations and consolidate previous findings. Such cross-level research implies that data should be collected at the level of individuals (e.g., through interviews) as well as teams 
(observation of team meetings and e-mail correspondence) and the organisation (analysis of strategy documents and organisational charts). Longitudinal research would be preferable, as relationship aspects may develop and influence each other over time. This would also allow for examining whether incremental changes will at some point lead to a qualitative change and a switch from one configuration to another, as suggested by configuration theorists (Meyer et al. 1993; Miller 1990). Hopefully, the presented literature review can provide a conceptual source for such configurational analyses of relationships in TNTs. 


\section{REFERENCES}

Adler, N.J. (1997), International Dimensions of Organizational Behavior, $3^{\text {rd }}$ ed. Cincinnati: South-Western College Publishing.

Baba, M.L., J. Gluesing, H. Ratner, and K.H. Wagner (2004), “The contexts of knowing: natural history of a globally distributed team”, Journal of Organizational Behavior, 25, 547-587.

Berg., N. (2006), „Globale Teams: Eine kritische Analyse des gegenwaertigen Forschungsstandes“, Zeitschrift fuer Personalforschung, 20 (3), 215-232.

Connaughton, S.L. and M. Shuffler (2007), "Multinational and multicultural teams. A review and future agenda”, Small Group Research, 38 (3), 387-412.

Cramton, C. D. (2001), “The mutual knowledge problem and its consequences for dispersed collaboration”, Organization Science, 12 (3), 346-371.

Cramton, C.D. and P. Hinds (2005), "Subgroup dynamics in internationally distributed teams. Ethnocentrism or cross-national learning?”, Research in Organizational Behavior, 26, 231-263.

Davison, S.C. and B.Z. Ekelund (2004), “Effective team process for global teams”, in Handbook of Global Management. A Guide to Managing Complexity, H.W. Lane, M.L. Maznevski, M.L. Mendenhall, and J. McNett (Eds.). Oxford: Blackwell, 227-249.

Davison, S.C. and K. Ward (1999), Leading International Teams. London: McGraw Hill. 
De Dreu, C.K. and L.R. Weingart (2003), “Task versus relationship conflict and team effectiveness. A meta-analysis”, Journal of Applied Psychology, 88, 741-749.

DiStefano, J. and M.L. Maznevski (2000), “Creating value with diverse teams in global management”, Organizational Dynamics, 29 (1), 45-63.

Earley, P.C. and H.K. Gardner (2005), “Internal dynamics and cultural intelligence in multinational teams”, in Managing Multinational Teams: Global Perspectives, D.L. Shapiro, Von M.A. Glinow, and J.L. Cheng, (Eds.). United Kingdom: Elsevier/JAI Press, 1-32.

Earley, C. and C.B. Gibson (2002), Multinational Work teams. A New Perspective. Mahwah, NJ: L.Erlbaum.

Earley, P.C. and E. Mosakowski (2000), “Creating Hybrid Team Cultures: An Empirical Test of Transnational Team Functioning”, Academy of Management Journal, 43 (1), 26-49.

Elron, E. (1997), “Top management teams within multinational corporations: Effects of cultural heterogeneity”, Leadership Quarterly, 8, 393-412.

Erez, M. and P.C. Earley (1993), Culture, Self-identity, and Work. New York: Oxford University Press. 
Fulk, J., P. Monge, and A.B. Hollingshead (2005), “Knowledge resource sharing in dispersed multinational teams: three theoretical lenses”, in Managing Multinational Teams: Global Perspectives, D.L. Shapiro, M.A. Von Glinow, and J.L. Cheng, (Eds.). United Kingdom: Elsevier/JAI Press, 155-188.

Gibbs, J.L. (2006), “Decoupling and coupling in global teams: implications for human resource management”, in Handbook of Research in International Human Resource Management G.K. Stahl and I. Bjorkman (Eds.). Cheltenham: Edward Elgar, 347-363.

Gibbs, J.L. (2009), "Dialectics in a global software team: Negotiating tensions across time, space, and culture”, Human Relations, 62 (6), 905-935.

Gibson, C.B. and J.L. Gibbs (2006), “Unpacking the concept of virtuality: The effects of geographic dispersion, electronic dependence, dynamic structure, and national diversity on team innovation”, Administrative Science Quarterly, 51, 451-495.

Gibson, C.B. and A.R. Grubb (2005), “Turning the tide in multinational teams”, in Managing Multinational Teams: Global Perspective, D.L. Shapiro, M.A. Von Glinow, and J.L. Cheng (Eds.). United Kingdom: Elsevier/JAI Press, 69-96.

Gibson, C.B. and J.A. Manuel (2003), “Building Trust”, in Virtual Teams that Work, C.B. Gibson, and S.G. Cohen (Eds.). San Francisco, Jossey-Bass, 59-86. 
Gibson, C.B. and F. Vermeulen (2003), “A healthy divide: Subgroups as a stimulus for team learning behaviour”, Administrative Science Quarterly, 48 (2), 202-239.

Gluesing, J.C. and C.B. Gibson (2004), “Designing and forming global teams”, in Handbook of Global Management. A Guide to Managing Complexity, H.W. Lane, M.L. Maznevski, M.L. Mendenhall, and J. McNett (Eds.). Oxford: Blackwell, 199-226.

Hackman, J.R. and G.R. Oldham (1980), Work Redesign. Reading, MA: Addison-Wesley. Hambrick, D.C., S.C. Davison, S.A. Snell, and C.C. Snow (1998), "When groups consist of multiple nationalities: Towards a new understanding of the implications”, Organization Studies, 19 (2), 181-205.

Henttonen, K. and K. Blomqvist (2004), “Managing distance in a global virtual team: The evolution of trust through technology-mediated relational communication”, Strategic Change, 14, 107-119.

Hinds, P.J. and M. Mortensen (2005), “Understanding conflict in geographically distributed teams: The moderating effect of shared identity, shared context, and spontaneous communication”, Organization Science, 16 (3), 290-307.

Janssens, M. and J.M. Brett (2006), “Cultural intelligence in global teams. A fusion model of collaboration”, Group and Organization Management, 31 (1), 124-153. 
Jarvenpaa, S.L. and D.E. Leidner (1999), “Communication and trust in global virtual teams”, Organization Science, 10 (6), 791-815.

Jarvenpaa, S.L., D.E. Knoll, and D.E. Leidner (1998), “Is anybody out there? The implications of trust in global virtual teams”, Journal of Management Information Systems, 14 (4), 29-64.

Jelinek, M. and J. Wilson (2005), “Macro influences on multicultural teams: a multi-level view”, in Managing Multinational Teams: Global Perspectives, D.L. Shapiro, M.A. Von Glinow, and J.L. Cheng (Eds.). United Kingdom: Elsevier/JAI Press, 209-232.

Joshi, A., G. Labianca, and P. Caligiuri (2002), “Getting along long distance: Understanding conflict in a multinational team through network analysis”, Journal of World Business, 27, 227284.

Kankanhalli, A., B. Tan, and K.K. Wei (2007), “Conflict and performance in global virtual teams”, Journal of Management Information Systems, 23 (3), 237-274.

Klimoski, R. and S. Mohammed (1994), “Team mental model: Construct or metaphor?”, Journal of Management, 20 (2), 403-437.

Kumar, K., P.C. Van Fenema, and M.A. Von Glinow (2005), “Intense collaboration in globally distributed work teams: Evolving patterns of dependencies ad coordination”, in Managing Multinational Teams: Global Perspectives, D.L. Shapiro, M.A. Von Glinow, and J.L. Cheng (Eds.). United Kingdom: Elsevier/JAI Press, 125-154. 
Lau, D.C. and J.K. Murnighan (1998) "Demographic diversity and faultiness: The compositional dynamics of organizational groups”, The Academy of Management Review, 23, 325-340.

Maznevski, M.L. (1994), “Understanding our differences: Performance in decision-making groups with diverse members”, Human Relations, 47, 531-552.

Maznevski, M.L. and N.A. Athanassiou (2006), “Guest editors’ introduction to the focussed issue: A new direction for global teams research”, Management International Review, 46 (6), 631-646.

Maznevki, M.L and K. Chudoba (2000), “Bridging space over time: Global virtual team dynamics and effectiveness”, Organization Science, 11 (5), 473-492.

Maznevski, M.L., S. C. Davison, and K. Jonsen (2006), “Global virtual team dynamics and effectiveness", in Handbook of Research in International Human Resource Management, G.K. Stahl and I. Bjorkman (Eds.). Cheltenham: Edward Elgar, 364-384.

McDonough, E.F. and D. Cedrone (2000), “Meeting the challenge of dispersed team management”, Research Technology Management, July-August, 12-17.

McGrath, J.E. (1984), Groups: Interaction and Performance. Englewood Cliffs, NJ: PrenticeHall. 
Mendenhall, M.E. (1999), “On the need for a paradigmatic integration in international human resource management”, Management International Review, 3, 65-87.

Meyer, A.D., A.S. Tsui, and C.R. Hinings (1993), “Configurational approaches to organizational analysis”, Academy of Management Journal, 36 (6), 1175-1195.

Miller, D. (1990), “Organizational configurations: cohesion, change, and prediction”, Human Relations, 43 (8), 771-789.

Miller, D. (1996), “Configurations revisited”, Strategic Management Journal, 17, 505-512.

Mortensen, M. and P.J. Hinds (2001), “Conflict and shared identity in geographically distributed teams”, International Journal of Conflict Management, 12 (3), 212-238.

Nahapiet, J. and S. Ghoshal (1998), "Social capital, intellectual capital, and the organizational advantage”, The Academy of Management Review, 23 (2), 242-226.

Oshri, I., P. Fenema, and J. Kotlarsky (2008), “Knowledge transfer in globally distributed teams: the role of transactive memory”, Information Systems Journal, March, 1-24.

Panteli, N. and R. Davison (2005), “The role of subgroups in the communication patterns of global virtual teams”, IEEE Transactions on Professional Communication, 48 (2), 191-200. 
Podsiadlowski, A. (2002), "Multicultural Workgoups: A differentiated view on group heterogeneity with regard to design and type of diversity”, Zeitschrift fuer Sozialpsychologie, 33 (4), 241-259.

Rousseau, D.M., S.B. Sitkin, R.S. Burt, and C. Camerer (1998), “Not so different after all: A cross-discipline view of trust. Academy of Management Review, 23 (3), 393-404.

Shapiro, D.L., S.A Furst, G.M. Spreitzer, and M.A. Von Glinow (2002), “Transnational teams in the electronic age: Are team identity and high performance at risk?” Journal of Organizational Behavior, 23, 455-467.

Shapiro, D.L., M.A. Von Glinow, and J.L. Cheng (2005), Managing Multinational Teams: Global Perspectives. United Kingdom: Elsevier/JAI Press.

Stahl, G., M.L. Maznevski, A. Voigt, and K. Jonsen (2007), “Unravelling the diversityperformance link in multicultural teams: Meta-analysis of studies on the impact of cultural diversity in teams”, INSEAD Faculty and Research Working Paper, 36/OB.

Sutanto, J., C.W. Phang, H.H. Kuan, A. Kankahalli, and B.C. Tan (2005), “Vicious and virtuous cycles in global virtual team role coordination”, Proceedings of the $38^{\text {th }}$ Hawaii international conference on system sciences.

Tajfel, H.H. (1982), “Social Identity and Intergroup Relations”, Cambridge, UK: Cambridge University Press. 
Tuckman, B. (1987), “Developmental sequence in small groups”, Psychological Bulletin, 63, 384-399.

Turner, J.C. (1987), Rediscovering the Social Group: A Self-Categorization Theory. Oxford: Blackwell.

Von Glinow, M.A., D.L. Shapiro, and J.M. Brett (2004), “Can we talk, and should we? Managing emotional conflict in multicultural teams”, Academy of Management Review, 29 (4), 578-592.

Zakaria, N., A. Amelinckx, and D. Wilemon (2004), "Working together apart? Building a knowledge-sharing culture for global virtual teams”, Creativity and Innovation Management, 13 (1), 15-29.

Zellmer-Bruhn, M. and C. Gibson (2006), “Multinational organization context: Implications for team learning and performance”, Academy of Management Journal”, 49 (3), 501-518.

Zimmermann, A., and P.R. Sparrow (2007), “Mutual adjustment processes in international teams: Lessons for the study of expatriation”, International Studies in Management and Organization, 37 (3), 65-88. 
Figure 1. Influences between Relationship Aspects as Indicated in the Reviewed Literature

\begin{tabular}{|c|c|c|c|c|c|c|c|c|}
\hline & $\begin{array}{l}\text { Team } \\
\text { identity }\end{array}$ & $\begin{array}{l}\text { Subgroup } \\
\text { formation }\end{array}$ & $\begin{array}{c}\text { Shared } \\
\text { understanding }\end{array}$ & Trust & Communication & $\begin{array}{l}\text { Knowledge } \\
\text { creation }\end{array}$ & Conflicts & $\begin{array}{c}\text { Interpersonal } \\
\text { affect }\end{array}$ \\
\hline $\begin{array}{c}\text { Shared } \\
\text { understanding }\end{array}$ & B & & - & & & & & \\
\hline Communication & A,B & A & A,B & A,B & - & & & \\
\hline $\begin{array}{c}\text { Knowledge } \\
\text { creation }\end{array}$ & A & A & A,B & A,B & A & - & & \\
\hline Conflicts & A,B & A & A,B & A & A,B & B & - & \\
\hline
\end{tabular}

A: Aspect on the top is reported to influence aspect on the left. B: Aspect on the left is reported to influence aspect on the top. 
Table 1. Configuration examples

\begin{tabular}{|c|c|c|}
\hline \multicolumn{3}{|c|}{ Configuration 1: Commitment and tight coupling } \\
\hline \multirow{3}{*}{$\begin{array}{l}\text { Factors } \\
\text { Strong cultural differences } \\
\text { High level of virtuality } \\
\text { High task interdependence }^{1}\end{array}$} & \multicolumn{2}{|l|}{ Relationship aspects } \\
\hline & Team identity & Strong \\
\hline & Subgroup formation & $\begin{array}{l}\text { Moderate, supports } \\
\text { team learning }\end{array}$ \\
\hline \multirow{9}{*}{$\begin{array}{l}\text { Strong integrative leadership } \\
\text { Strong shared goals } \\
\text { High interdependence between } \\
\text { organisational units } \\
\text { Emphasis on organisational } \\
\text { integration }\end{array}$} & Role expectations & Highly clear \\
\hline & Shared understanding & High \\
\hline & Trust & High \\
\hline & Communication & Highly effective \\
\hline & $\begin{array}{l}\text { Knowledge creation, } \\
\text { innovation }\end{array}$ & $\begin{array}{l}\text { High across } \\
\text { subgroups }\end{array}$ \\
\hline & Contribution of effort & High \\
\hline & Conflicts & Constructive \\
\hline & Interpersonal affect & Highly developed \\
\hline & Satisfaction & High \\
\hline
\end{tabular}

\begin{tabular}{|l|l|l|}
\hline Configuration 2: Commitment and loose coupling \\
\hline Factors & Relationship aspects \\
\hline $\begin{array}{l}\text { Strong cultural differences } \\
\text { High level of virtuality } \\
\text { Low task interdependence } \\
\text { Weak integrative leadership }\end{array}$ & Team identity & Strong \\
\cline { 2 - 3 } $\begin{array}{l}\text { Strong shared goals } \\
\text { Weak interdependence between } \\
\text { organisational units } \\
\text { Emphasis on localisation }\end{array}$ & Subgroup formation & $\begin{array}{l}\text { Strong, supports } \\
\text { learning within } \\
\text { organisational } \\
\text { subunits }\end{array}$ \\
\cline { 2 - 3 } & Role expectations & Less clear \\
\cline { 2 - 3 } & Shared understanding & Lower \\
\cline { 2 - 3 } & Trust & Possibly lower \\
\cline { 2 - 3 } & Communication & Sufficiently effective \\
\cline { 2 - 3 } & $\begin{array}{l}\text { Knowledge creation, } \\
\text { innovation }\end{array}$ & $\begin{array}{l}\text { High within local } \\
\text { subunit } \\
\text { Sufficient exchange } \\
\text { between subgroups }\end{array}$ \\
\hline & & High \\
\hline & Contribution of effort & Less developed \\
\cline { 2 - 3 } & Conflicts & High \\
\cline { 2 - 3 } & Interpersonal affect & Satisfaction \\
\hline
\end{tabular}

L

${ }^{1}$ Differences between configurations underlined 